\title{
Political Factors Affecting Parents' Perceptions on Televised Polio Messages in Sindh, Pakistan: A Critical Investigation
}

\author{
FARHEEN QASIM NIZAMANI \\ University of Sindh, Pakistan \\ SITI ZANARIAH AHMAD ISHAK \\ Universiti Malaysia Sarawak \\ MUHAMMAD QASIM NIZAMANI \\ University of Sindh, Pakistan
}

\begin{abstract}
Television messages are one of the essential means to disseminate polio messages in the prevention of infectious diseases. However, little is known about the hegemony of political actors specifically government in power over televised health content and its impact on people's perceptions to adopt or reject a health attitude, particularly in developing countries. Theoretically, Bandura in his social cognitive theory (1997) has examined the change in mind-sets through observational learning, media and social surroundings. However, his research lacks to underline state dominancy over people's health decisions with reference to political leadership. This study fills the gap by critically investigating political factors that obstruct Pakistani television channels to disseminate productive and informative polio messages, for boosting self-efficacy among lower middle class Jamshoro parents, thus encouraging them to vaccinate their children against polio in Sindh province of Pakistan. The methodological approach employs critical paradigm with qualitative investigation through in-depth interviews. Low level of awareness, less credibility of television channels and political hegemony over health messages contributed and enlarged self-efficacy to collective efficacy of political actors during findings of this research study as a new domain in social cognitive theory. In addition, this research sheds light by critically analysing the elements of corruption, unaccountability and lack of transparency involved in ineffective televised polio messages in developing nations as Pakistan, opening a space for policy makers and television officials for a positive health change in designing health awareness campaigns.
\end{abstract}

Keywords: Television messages, parents' perceptions, polio, political hegemony, collective efficacy.

\section{INTRODUCTION AND BACKGROUND}

Televised health messages always increase and strengthen the knowledge of targeted contagious diseases and health to a wider audience. The purpose of these health messages is to educate and inform large number of parents for vaccinating their children. Health education programmes in Pakistan started during the year 1990 through the collaboration with international health institutions. Unfortunately, health being the most imperative sector for human prosperity was not considered as a matter of concern to provide a better health to its citizens (Murtaza, Mustafa \& Awan, 2015), distressing child health at large.

Pakistan is still one of the three countries of the world that has highest transmission of poliovirus (Ghafoor \& Sheikh, 2016). An estimated US $\$ 2.5$ million was being consumed in Pakistan alone to focus on the elimination of polio for 2013 (GPEI, 2014). Even then, Global Polio Eradicative Initiative Report (2014) suggested that the incapability of government to overcome this enduring disease intensified morbidity and mortality rates among children 